\title{
Sosialisasi Penggunaan Tanaman Herbal untuk Diabetes Mellitus dan Pemeriksaan Kadar Gula Darah Di Desa Kandangan Baru Kecamatan Panyipatan Tanah Laut
}

\author{
Hasniah $^{1}$, Muhammad Fauzi ${ }^{2}$, Fauzi Rahman $^{3}$, Aris Fadillah $^{4}$, Karina Erlianti $^{5}$, Juwita Ramadhani ${ }^{6}$ \\ Didi Susanto ${ }^{7}$ \\ Farmasi, Universitas Islam Kalimantan Muhammad Arsyad Al Banjari Banjarmasin, Indonesia ${ }^{1,2,3,4,5,6,7}$ \\ E-mail: hasniahhapt@gmail.com ${ }^{1}$, fauzi.ozi1294@gmail.com ${ }^{2}$, fauzi.rahmanpharmacy@gmail.com ${ }^{3}$, \\ aris.f.6593@gmail.com ${ }^{4}$, karina.erlianti@gmail.com ${ }^{5}$, juwitarha@ gmail.com ${ }^{6}$, didisusanto82@ yahoo.co.id ${ }^{7}$
}

\begin{abstract}
Abstrak
Diabetes melitus adalah salah satu penyakit degeneratif yang saat ini menjadi masalah kesehatan masyarakat yang serius. Pelaksanaan kegiatan sosialisasi di Desa Kandangan Baru, Kecamatan Panyipatan, Kabupaten Tanah Laut yang merupakan desa dengan mata pencarian utama penduduknya adalah bertani. Berdasarkan peneliatian menunjukkan diabetes mellitus pada petani di Indonesia cukup besar yaitu 6,2\% yang terjadi kenaikan lebih dari 2 kali lipat dari tahun 2007 adalah sebesar 2,8\%. Oleh karena itu, diperlukan adanya pengabdian masyarakat yang tergerak untuk memberikan bantuan pengabdian berupa sosialisasi tentang pencegahan dan pemanfaatan tanaman herbal dalam rangka pencegahan penyakit diabetes mellitus. Metode yang digunakan yaitu model presentasi (penyampaian materi) juga tanya jawab serta pemeriksaan kadar gula darah. Hasil menunjukkan dengan adanya penyuluhan dan pemeriksaan kadar gula darah ini dapat memberikan data serta pengetahuan dalam hal pencegahan serta penindakan penyakit dengan pengaturan pola hidup sehat, serta penggunaan tanaman herbal sebagai alternatif pengobatan. Untuk masyarakat yang belum pernah melaksanakan pengecekan kesehatan, bisa menjadi pengenalan awal untuk mengenali status kesehatannya, sehingga bisa merubah perilaku pola hidup sehat. Kegiatan penyuluhan berjalan dengan mudah serta masyarakat mencermati dengan bersemangat, Dari 23 orang yang dicek kadar gula darahnya ditemui 2 orang dengan kandungan gula darah melebihi nilai normal (>200 mg/dl).
\end{abstract}

Kata kunci: diabetes mellitus, kadar gula darah, penyuluhan, pemeriksaan

\begin{abstract}
Diabetes mellitus is a degenerative disease which is currently a serious public health problem. The implementation of socialization activities in Kandangan Baru Village, Panyipatan District, Tanah Laut Regency, which is a village whose main livelihood is farming. Based on research, it shows that diabetes mellitus among farmers in Indonesia is quite large, namely 6.2\%, which is an increase of more than 2 times from 2007, which is 2.8\%. Therefore, it is necessary to have community service that is motivated to provide service assistance in the form of socialization on the prevention and use of herbal plants in the context of preventing diabetes mellitus. The method used is a presentation model (delivery of material) as well as questions and answers and checking blood sugar levels. The results showed that the counseling and examination of blood sugar levels could provide data and insights in the prevention and action of diseases by regulating a healthy lifestyle, as well as the use of herbal plants as an alternative treatment. For people who have never carried out health checks, it can be an early introduction to identify their health status so that they can change their behavior to a healthy lifestyle. Extension activities run easily and the community is watching with enthusiasm. Of the 23 people whose blood sugar levels were checked, 2 were found with blood sugar levels above normal values (> $200 \mathrm{mg} / \mathrm{dl}$ ).
\end{abstract}

Keywords: Diabetes Mellitus, blood sugar levels, counseling, examination

Copyright (c) 2021 Hasniah, Muhammad Fauzi, Fauzi Rahman, Aris Fadillah, Karina Erlianti, Juwita Ramadhani, Didi Susanto

$\triangle$ Corresponding author

Address : Universitas Islam Kalimantan MAB

Email : Hasniahhapt@gmail.com

ISSN 2721- 9224 (Media Cetak)

DOI : https://doi.org/10.31004/abdidas.v2i3.318

ISSN 2721-9216 (Media Online) 
552 Sosialisasi Penggunaan Tanaman Herbal untuk Diabetes Melitus dan Pemeriksaan Kadar Gula Darah di Desa Kandangan Baru Kecamatan Panyipatan Tanah Laut - Hasniah, Muhammad Fauzi, Fauzi Rahman, Aris Fadillah, Karina Erlianti, JuwitaRamadhani, Didi Susanto

DOI: https://doi.org/10.31004/abdidas.v2i3.318

\section{PENDAHULUAN}

Diabetes mellitus tumbuh secara eksponensial dengan proporsi epidemi di seluruh dunia (Liu et al., 2010). Penyakit ini termasuk penyakit tidak menular yang jadi fokus karena menjadi penyebab kematian bagi negara yang berpendapatan kecil serta menengah pada tahun 2030 (Angell et al., 2020). Pengecekan kadar gula darah bagi penderita amat berarti sebab bisa menjadi pengontrol penyakit sehingga mencegah komplikasi yang berat serta lebih membiasakan pola makan yang sehat serta aktivitas fisiknya (Petrov, 2021).

Masalah penyakit degeneratif perlu memperoleh perhatian yang lebih serius dari pemerintah serta praktisi kesehatan, sebab pada perkembangannya memunculkan kasus yang diakibatkan oleh keterbatasan keahlian ekonomi serta pengetahuan pola hidup sehat. Keterbatasan itu menimbulkan orang tanpa sadar melaksanakan aksi yang menurunkan kualitas hidup, tidak berobat ke sarana kesehatan, tidak taat imbauan dokter, tidak melaksanakan pola hidup sehat, dan konsumsi bermacam tumbuhan serta racikan obat konvensional tanpa menguasai khasiat serta metode konsumsi dengan cara betul (Suiraoka, 2012).

Kesehatan adalah perihal yang sangat berarti untuk tiap orang, dengan memiliki badan yang sehat masyarakat sanggup melaksanakan aktivitasnya dengan baik tanpa menghadapi kesusahan. Desa Kandangan Baru merupakan salah satu desa yang terdapat di Kecamatan Panyipatan Kabupaten Tanah Laut. Kandangan
Baru ialah desa dengan mata pencarian penduduknya merupakan bertani. Riskesdas 2013 membuktikan kebiasaan diabetes mellitus pada orang yang bertani di Indonesia lumayan besar ialah 6,20\% yang hadapi kenaikan lebih dari 2 kali lipat dari tahun 2007 ialah sebesar 2,8\%. Bagi riset tingginya kebiasaan diabetes mellitus pada petani di pedesaan bisa diakibatkan oleh sebagian perihal salah satunya adalah pola makan sehingga lebih rentan menderita diabetes (Kementerian Kesehatan Republik Indonesia, 2018).

Oleh karena itu, diperlukan adanya pengabdian masyarakat yang tergerak untuk memberikan bantuan pengabdian berupa sosialisasi pemanfaatan tanaman herbal dalam rangka pencegahan penyakit diabetes mellitus bagi masyarakat di desa Kandangan Baru, Kecamatan Panyipatan, Kabupaten Tanah Laut. Seperti diketahui, perempuan memiliki andil berarti dalam menjaga serta melindungi kesehatan keluarganya (Kuswinarti et al., 2014), dengan harapan dapat meneruskan informasi tersebut pada keluarga dan sekitarnya agar masyarakat sadar betapa pentingnya menjaga kesehatan. Selanjutnya peningkatan wawasan tersebut akan dapat bermanfaat sebagai upaya pencegahan dan penanggulangan penyakit diabetes mellitus.

\section{METODE}

Melakukan penyuluhan yang dilaksanakan pada hari Sabtu, bertepatan 20 Februari 2021 di Kantor Kelurahan Desa Kandangan Baru pada Ibuibu PKK, penyuluhan ini dilakukan untuk meningkatkan pengetahuan masyarakat mengenai 
diabetes dan penggunaan tanaman herbal yang benar. Sebelum materi diberikan tim pelaksana membagikan soal pretest, materi yang pertama mengenai diabetes mellitus seperti gejalanya, pencegahannya, komplikasi, yang kedua mengenai tanaman herbal sambiloto sebagai pengobatan alternatif, bagaimana cara pembuatan dan penggunaannya, selanjutnya memberikan materi tentang pola hidup yang sehat serta tanya jawab atau diskusi yang dilakukan untuk meningkatkan pemahaman masyarakat. Selanjutnya pemeriksaan kadar gula darah bagi masyarakat yang belum sempat melaksanakan pemeriksaan, pemeriksaan kesehatan itu bisa berperan sebagai skrining kesehatan untuk mengenali status kesehatan secara dini agar dapat melakukan pencegahan. Untuk penderita diabetes, terkontrolnya status kesehatan bisa menghindari ataupun paling tidak memperlambat timbulnya komplikasi yang berat. Setelah melakukan pemeriksaan kadar gula darah peserta wajib mengisi posttest yang dibagikan.

\section{HASIL DAN PEMBAHASAN}

\section{Penyuluhan dan Penyampaian Materi Pencegahan dan Penanganan Diabetes}

Kegiatan pengabdian ini dilaksanakan pada hari Sabtu bertepatan pada 20 Februari 2021 mulai pkl. 07.30 Waktu indonesia tengah (WITA) di Kantor Kelurahan Desa Kandangan Baru. Penyampaian materi oleh ibu Apt. Hasniah, M. Farm selaku ketua pengabdian, materi yang di berikan yaitu diabetes mellitus ataupun kencing manis merupakan sesuatu penyakit dimana kadar gula darah dalam kondisi puasa $>110$ miligram/dl serta dalam kondisi tidak puasa>200 miligram/dl. Pertanda umum yang biasa terjadi pada pengidap diabetes yaitu berat badan menurun cepat, kerap membuang air kecil, cepat letih serta mengantuk, sering merasa lapar serta gatal-gatal di sekitar kemaluan. Komplikasi yang banyak terjadi pada penyakit diabetes mellitus di antaranya gagal ginjal, luka yang sukar sembuh hingga menimbulkan amputasi bagi penderitanya, impotensi, penyakit jantung, stroke, kebutaan, dan hipoglikemia yang bisa menimbulkan penderitanya tidak sadarkan diri. Pencegahan penyakit diabetes bisa dilakukan dengan pola hidup yang lebih sehat paling utama pada penderita diabetes tipe 2 (Olokoba, Obateruand Olokoba, 2012), pola makan yang sehat dan penggunaan nutrisi yang sesuai, bila kalori terlalu berlebihan dalam waktu yang lama dapat menimbulkan penyakit diabetes (Basri et al., 2018).

Prevalensi diabetes terus bertambah diakibatkan cara pola makan masyarakat yang kerap menggunakan makanan yang kurang sehat semacam hidangan fast food tidak hanya itu, minimnya kegiatan berolahraga bisa jadi salah satu cara untuk pencegahan (Korczak, et al., 2011). Pada kegiatan sosialisasi ini pula disarankan pada masyarakat untuk mengubah hidup yang lebih sehat, seperti diet sehat, mengurangi stres dan berolahraga ataupun kegiatan aktivitas fisik yang teratur. Waspada terhadap penyakit diabetes diinformasikan juga oleh pemateri, sehingga direkomendasikan untuk berhati-hati sebab penyakit ini menyerang secara perlahan lahan serta kadang tidak dikenali. Minimnya pengetahuan 

di Desa Kandangan Baru Kecamatan Panyipatan Tanah Laut - Hasniah, Muhammad Fauzi, Fauzi Rahman, Aris Fadillah, Karina Erlianti, JuwitaRamadhani, Didi Susanto

DOI: https://doi.org/10.31004/abdidas.v2i3.318

masyarakat tentang bahaya ancaman penyakit diabetes mellitus, serta pengendaliannya menimbulkan penyakit ini terus bertambah banyak dikalangan masyarakat (Bruce, 2003). Kegiatan sosialisasi ini diharapkan bisa memutuskan keterbatasan pengetahuan masyarakat mengenai pencegahan, pengendalian penyakit diabetes serta penggunaan tanaman herbal. Dari kegiatan ini dilihat dari (gambar 2). didapatkan nilai hasil peningkatan pengetahuan peserta yang ikut serta dalam acara. Masyarakat diharapkan dapat mencegah terjadinya penyakit diabetes, tata cara penggunaan tanaman herbal yang benar, tidak hanya itu saja masyarakat yang menderita diabetes dan orang terdekat bisa mengenali pengobatan diabetes yang sesuai, dengan itu dapat menghindari progresivitas penyakit diabetes.

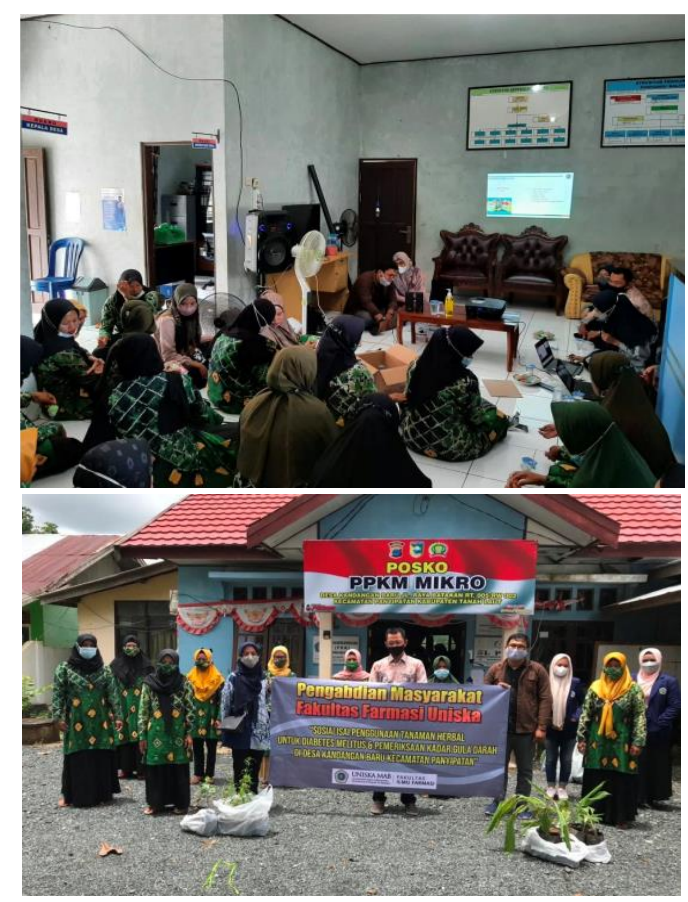

Gambar 1. Sosialisasi dan Penyampaian Materi tentang Diabetes Mellitus
Tabel 1. Jumlah Responden

\begin{tabular}{|l|l|c|c|}
\hline No. & \multicolumn{1}{|c|}{ Uraian } & $\begin{array}{c}\text { Jumlah } \\
\text { Responden }\end{array}$ & Persentase \\
\hline 1. & Pre Test & 23 & $50 \%$ \\
\hline 2. & Post Test & 23 & $85 \%$ \\
\hline
\end{tabular}

\section{Kenaikan Score Pre Test dan Post}

Test dari 23 orang

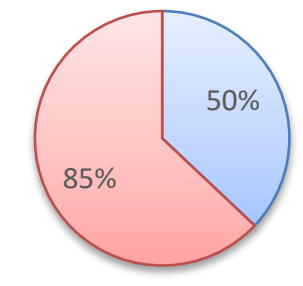

$\square$ Pre Test $\quad \square$ Post Test

Gambar 2. Rata-rata Score Pretest dan Post-test

Penggunaan tanaman herbal sebagai alternatif pengobatan diabetes mellitus yaitu sambiloto adalah salah satu tanaman yang dikenal serta banyak dipakai oleh masyarakat Indonesia, sambiloto adalah salah satu tumbuhan herbal yang mempunyai manfaat sebagai obat untuk diabetes (Adha et al., 2019) Penelitian-penelitian tentang sambiloto (Andrographispaniculata) dengan penyakit diabetes sudah banyak dicoba. Herbal sambiloto jadi salah satu dari 3 puluh ribu tumbuhan obat yang jadi pengembangan serta riset oleh lembaga/badan di Indonesia seperti Kementrian, BPOM, GP Jamu, serta Saintifikasi Jamu. Daun sambiloto memiliki kandungan andrografolid, deoksiandrografolid, neoandrografolid, $14-$ deoksididehidroandrografolid serta homoandrografolid yang mempunyai khasiat anti diabetes (Sudarsono, 

di Desa Kandangan Baru Kecamatan Panyipatan Tanah Laut - Hasniah, Muhammad Fauzi, Fauzi Rahman, Aris Fadillah, Karina Erlianti, JuwitaRamadhani, Didi Susanto

DOI: https://doi.org/10.31004/abdidas.v2i3.318

Pudjoarinto. A., Gunawan, D., Wahyuono, S., Donatus, I.A., Drajad, M., Wibowo, S., 2006).

\section{Pemeriksaan Kadar Gula Darah}

Dilakukan juga kegiatan pemeriksaan kesehatan dalam berbentuk pengecekan kadar gula darah sewaktu dengan gratis pada ibu-ibu anggota
PKK yang berjumlah 23 orang (tabel 1). Pemeriksaan gula darah dilakukan oleh Muhammad Fauzi, M.Farm selaku kepala laboratorium farmasi sekaligus anggota pengabdian Universitas Islam Kalimantan MAB Banjarmasin.

Tabel 2. Hasil Pemeriksaan

\begin{tabular}{|c|c|c|c|c|c|c|}
\hline No & Nama Usia & Pekerjaan & Usia & $\begin{array}{c}\text { Riwayat } \\
\text { penyakit }\end{array}$ & $\begin{array}{c}\text { Hasil } \\
\text { Pemeriksaan }\end{array}$ & Keterangan \\
\hline 1. & Maysarah & IRT & 18 & Maagh & 94 & Normal \\
\hline 2. & Yanti & IRT & 28 & Maagh & 80 & Normal \\
\hline $\mathbf{3 .}$ & Hj. Nurdiyana & IRT & $\mathbf{5 7}$ & Hipertensi & $\mathbf{2 7 6}$ & Tinggi \\
\hline 4. & Raudaniah & IRT & 34 & Asam Urat & 135 & Normal \\
\hline 5. & Fitriani & IRT & 40 & Hipertensi & 127 & Normal \\
\hline 6. & Marlina & IRT & 47 & Hipertensi & 122 & Normal \\
\hline 7. & Wahidah & IRT & 36 & Hipertensi & 137 & Normal \\
\hline 8. & Saufia & IRT & 43 & Hipertensi & 88 & Normal \\
\hline 9. & Heny Purwati & IRT & 48 & Hipertensi & 102 & Normal \\
\hline 10. & Marini & IRT & 32 & Hipertensi & 127 & Normal \\
\hline 11. & Maskanah & IRT & 52 & Hipertensi & 92 & Normal \\
\hline 12. & Rohani & IRT & 43 & Hipertensi & 117 & Normal \\
\hline 13. & Hj. Normah & IRT & 52 & Hipertensi & 135 & Normal \\
\hline 14. & Rusdiana & IRT & 46 & Hipertensi & 112 & Normal \\
\hline 15. & Jumiati & IRT & 38 & Hipertensi & 96 & Normal \\
\hline 16. & Linawati & IRT & 34 & Hipertensi & 82 & Normal \\
\hline 17. & Marliana & IRT & 41 & Hipertensi & 102 & Normal \\
\hline $\mathbf{1 8 .}$ & Badiah & IRT & $\mathbf{4 7}$ & Hipertensi & $\mathbf{2 0 8}$ & Tinggi \\
\hline 19. & Anita & IRT & 39 & Hipertensi & 117 & Normal \\
\hline 20. & Hamisah & IRT & 32 & Hipertensi & 82 & Normal \\
\hline 21. & Jahriah & IRT & 36 & Hipertensi & 92 & Normal \\
\hline 22. & Dinah & IRT & 54 & Hipertensi & 106 & Normal \\
\hline 23. & Mariana & IRT & 52 & Hipertensi & 127 & Normal \\
\hline
\end{tabular}

Kegiatan pengukuran gula darah sewaktu pada Ibu-ibu PKK desa Kandangan Baru sudah dicoba. Dengan 23 orang partisipan dengan rentang usia 18 tahun hingga 57 tahun, profesi umum partisipan ialah ibu rumah tangga (Tabel 1). Diantara partisipan memang mempunyai riwayat penyakit diabetes, serta darah tinggi. Berikutnya partisipan diarahkan untuk melakukan pencegahan penyakit serta penanganan diabetes yang sudah disampaikan oleh pemateri. Hasil pengecekan pengukuran kadar gula darah sewaktu bisa diamati pada Tabel 2.

Dari 23 orang yang dilakukan pemeriksaan kadar gula darahnya ditemui 2 orang dengan kadar gula darah melampaui batasan wajar >200 miligram/dl ialah 276 miligram/dl, serta 208 

di Desa Kandangan Baru Kecamatan Panyipatan Tanah Laut - Hasniah, Muhammad Fauzi, Fauzi Rahman, Aris Fadillah, Karina Erlianti, JuwitaRamadhani, Didi Susanto

DOI: https://doi.org/10.31004/abdidas.v2i3.318

miligram/dl (dalam tabel dicetak tebal). Kedua orang itu diberikan himbauan lebih lanjut mengenai diabetes serta bahayanya, dan diberikan juga arahan sehingga dapat menjauhi terbentuknya komplikasi, dari kedua orang dengan kandungan kadar gula darah yang tinggi itu antara lain berumur 40 tahun keatas. Dua orang itu mempunyai riwayat penyakit diabetes hipertensi. Dari kegiatan penyuluhan ini berdasarkan hasil pretest dan post-test didapat peningkatan pengetahuan masyarakat mengenai diabetes seperti faktor resiko, gejala, komplikasi, pengobatan dan pola hidup yang sehat, serta penggunaan tanaman herbal sambiloto yang benar sebagai terapi alternatif pada diabetes, sehingga dengan adanya peningkatan pengetahuan ini masyarakat mampu melakukan pencegahan penyakit diabetes mellitus dengan melakukan pola hidup yang sehat dan penggunaan tanaman herbal yang benar, sehingga kasus diabetes Desa Kandangan baru panyipatan tanah laut tidak bertambah.

\section{SIMPULAN}

Kegiatan sosialisasi dalam bentuk penyuluhan sangat berguna karena tingkatkan pengetahuan masyarakat mengenai diabetes mellitus dan penggunaan tanaman herbal yang benar meningkat dikalangan masyarakat. Pencegahan dan waspada masyarakat mengenai penyakit ini bertambah, kegiatan pemeriksaan kadar gula darah harus dilakukan dengan teratur kepada masyarakat agar identifikasi dini penyakit diabetes mellitus dapat diketahui, sehingga komplikasi dapat dicegah lebih dahulu sebelum terjadi komplikasi yang lebih serius.

\section{UCAPAN TERIMAKASIH}

Terimakasih kami sampaikan kepada ketua PKK dan anggota PKK serta masyarakat sekitar Desa Kandangan Baru, Kecamatan Panyipatan, Tanah laut, Kalimantan Selatan yang telah memberikan waktu dan kesempatannya kepada kami untuk melaksanakan kegiatan sosialisasi kami.

\section{DAFTAR PUSTAKA}

Adha, S. A., Febriyanti, R. M., \& Milanda, T. (2019). Review: Potensi Sambiloto Sebagai Obat Antidiabetes Berbasis Herbal a Review: Potential of Sambiloto As Herbal Based Antidiabetic Medicine. Medical Sains, 4(1), 7-12.

Angell, S. Y., Mcconnell, M. V., Anderson, C. A. M., Bibbins-Domingo, K., Boyle, D. S., \& Capewell. (2020). The american heart association 2030 impact goal: A presidential advisory from the american heart association. Circulation, 120-138.

Basri, H. M., Harastuti, \& S., R. (2018). Hubungan Status Nutrisi Dan Kecemasan Dengan Proses Penyembuhan Luka Diabetes Mellitus Di Ruang Rawat Inap Bedah Rsud Barru. Jurnal Ilmiah Kesehatan Diagnosis, 12, 476481.

Bruce, D. G. (2003). Pendidikan dan pengetahuan diabetes pada pasien dengan diabetes tipe 2 dari komunitas: The Fremantle Diabetes Study. 17(2), 82-89.

Kementerian Kesehatan Republik Indonesia. (2018). Riset Kesehatan Dasar. Badan Penelitian dan Pengembangan Kesehatan Kementerian Kesehatan RI.

Kuswinarti, Sitorus, T., \& Ruslan, A. (2014). Pemberdayaan wanita dengan Peningkatan tentang Obat, Pembudidayaan Tanaman Obat dan Pembuatan Berbagai sediaan Obat 
557 Sosialisasi Penggunaan Tanaman Herbal untuk Diabetes Melitus dan Pemeriksaan Kadar Gula Darah di Desa Kandangan Baru Kecamatan Panyipatan Tanah Laut - Hasniah, Muhammad Fauzi, Fauzi Rahman, Aris Fadillah, Karina Erlianti, JuwitaRamadhani, Didi Susanto

DOI: https://doi.org/10.31004/abdidas.v2i3.318

Herbal untuk Penyakit- Penyakit umum di Masyarakat di Desa Sadari dan Haurseah Kecamatan Argapura Kabupaten Majalengka. Dharmakarya, 3(1).

Liu, Z., Fu, C., Wang, W., \& Xu, B. (2010). Prevalence of Cronic Complication of Type 2 Diabetes Mellitus Outpatients: a Cross Sectional Hospital Based Survey in Urban China. Health and Quality of Life Outcomes, $8(1), 62-67$.

Suiraoka. (2012). Mengenal, Mencegah, dan Mengurangi Faktor Risiko 9 Penyakit Degeneratif. Nuha Medika. 